\title{
ERRATUM
}

\section{Abstracts from the Japanese Journal of Limnology}

\section{Limnology (2004) 5:57-60}

An error appeared in the section "Abstracts from the Japanese Journal of Limnology." The abbreviation of the journal was incorrectly shown as Jap J Limnol. The correct abbreviation is Jpn J Limnol. 